\title{
A fixed-dose combination of memantine extended-release and donepezil in the treatment of moderate-to-severe Alzheimer's disease
}

This article was published in the following Dove Press journal:

Drug Design, Development and Therapy

3 October 2016

Number of times this article has been viewed

\author{
William James Deardorff \\ George T Grossberg \\ Department of Psychiatry, St Louis \\ University School of Medicine, \\ St Louis, MO, USA
}

\begin{abstract}
Currently available therapies for the treatment of Alzheimer's disease (AD) consist of cholinesterase inhibitors (ChEIs), such as donepezil, and the $N$-methyl-D-aspartate receptor antagonist memantine. In December 2014, the US Food and Drug Administration approved Namzaric ${ }^{\mathrm{TM}}$, a once-daily, fixed-dose combination (FDC) of memantine extended-release (ER) and donepezil for patients with moderate-to-severe AD. The FDC capsule is bioequivalent to the coadministered individual drugs, and its bioavailability is similar when taken fasting, with food, or sprinkled onto applesauce. The combination of memantine and ChEIs in moderateto-severe AD provides additional benefits to ChEI monotherapy across multiple domains and may delay the time to nursing home admission. A dedicated study of memantine ER compared to placebo in patients on a stable dose of a ChEI found statistically significant benefits on cognition and global status but not functioning. Treatment with memantine ER and donepezil is generally well tolerated, although higher doses of ChEIs are associated with more serious adverse events such as vomiting, syncope, and weight loss. Potential advantages of the FDC include a simpler treatment regimen, reduction in pill burden, and the ability to sprinkle the capsule onto soft foods. Patients who may benefit from the FDC include those with significant dysphagia, a history of poor compliance, or limited caregiver interaction. However, available evidence that these advantages would increase treatment adherence and persistence is conflicting, meaning that the added cost of switching patients from generic options to an FDC may not always be justified.
\end{abstract}

Keywords: Alzheimer's disease, cholinesterase inhibitor, donepezil, fixed-dose combination, memantine

\section{Introduction}

Alzheimer's disease (AD) is the most common major neurocognitive disorder and affects an estimated $11 \%$ of people aged 65 years and older and $32 \%$ of people aged 85 years and older in the United States. ${ }^{1}$ An estimated 46.8 million people worldwide in 2015 were living with dementia, and this number is projected to almost double every 20 years to reach 131.5 million in $2050 .^{2}$ The estimated total cost of AD in the United States in 2010 after accounting for care purchased in the marketplace (nursing home care, Medicare spending, out-of-pocket spending, and formal home care) and informal care provided by caregivers was between $\$ 159$ billion and $\$ 215$ billion. ${ }^{3}$ Treatment of AD consists of symptomatic therapies as no US Food and Drug Administration (FDA)-approved drugs have been shown to prevent, delay, or halt the progression of disease. In the early stages of AD, cholinesterase inhibitors (ChEIs) such as donepezil, galantamine, and rivastigmine are often used. Memantine, an $N$-methyl-D-aspartate
Correspondence: George T Grossberg Department of Psychiatry, St Louis University School of Medicine, 1438 South Grand St Louis, MO 63104, USA

Tel +I 3 I4 9774829

Fax + I 3149774878

Email grossbgt@slu.edu
Drug Design, Development and Therapy 2016:10 3267-3279

3267

Dovepress f $y$ in $\mathbf{0}$

http://dx.doi.org/10.2147/DDDTS86463"

(c) (1) \&) $\odot 2016$ Deardorff and Grossberg. This work is published and licensed by Dove Medical Press Limited. The full terms of this license are available at https://www.dovepress.com/terms.php

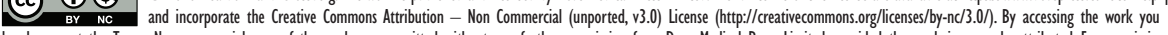
hereby accept the Terms. Non-commercial uses of the work are permitted without any further permission from Dove Medical Press Limited, provided the work is properly attributed. For permission for commercial use of this work, please see paragraphs 4.2 and 5 of our Terms (https://www.dovepress.com/terms.php). 
(NMDA) receptor antagonist, is indicated for use in patients with moderate-to-severe AD.

The combination of a ChEI and memantine is currently the standard of care in the treatment of moderate-to-severe AD. Several pooled analyses demonstrate that combination therapy results in significant benefits in cognition and global clinical status beyond that of ChEI monotherapy, although the clinical relevance of these benefits has been called into question..$^{4-8}$ The recent European Federation of Neurological Societies panel on dementia ultimately recommended the use of combination therapy over ChEI monotherapy. ${ }^{9}$ The recommendation was considered weak with respect to activities of daily living, cognitive functioning, and global clinical impression, but strong with respect to behavior.

In June 2010, a once-daily extended-release (ER) memantine capsule was approved by the FDA, offering a more convenient regimen compared to twice-daily memantine immediate-release (IR) tablets. ${ }^{10}$ In December 2014, the FDA approved a once-daily fixed-dose combination (FDC) of memantine ER and donepezil (Namzaric ${ }^{\mathrm{TM}}$, Allergan, Inc., Irvine, CA, USA) for the treatment of moderate-tosevere AD in patients already stabilized on memantine and donepezil. ${ }^{11}$ In July 2016, the FDA expanded the label to include its use in patients stabilized only on donepezil. This paper will review the pharmacodynamics and pharmacokinetics of the FDC, clinical efficacy data of combination therapy, safety and tolerability data, economic studies, and data on treatment adherence in AD.

\section{Pharmacodynamics and biochemical rationale for combination therapy}

Pathologically, $\mathrm{AD}$ is characterized by extracellular plaques composed of amyloid- $\beta$ and intracellular neurofibrillary tangles composed of hyperphosphorylated tau protein. Aberrant processing of amyloid precursor protein leads to plaque formation. When the microtubule-associated protein tau becomes hyperphosphorylated, it loses its ability to stabilize microtubules, resulting in impaired axonal transport. The deposition of these proteins and the accompanying inflammatory response results in neuronal cell death, synaptic dysfunction, and decreased neurotransmission. ${ }^{12}$ Dysfunction in cholinergic neurons in the basal and rostral forebrain results in early cognitive impairments in $\mathrm{AD} \cdot{ }^{13} \mathrm{ChEIs}$, like donepezil, act by inhibiting the enzyme acetylcholinesterase, an enzyme responsible for the breakdown of acetylcholine. Cholinesterase inhibition results in greater amounts of acetylcholine, which appears to improve cognition by enhancing cholinergic transmission.
As one of the major neurotransmitters involved in excitatory pathways, glutamate plays an important role in cortical and hippocampal pathways via the NMDA receptor. NMDA receptor activation allows an influx of calcium ions into the postsynaptic neuron, triggering pathways important in synaptic plasticity. ${ }^{13}$ However, it is thought that overactivation of NMDA receptors may lead to neurodegeneration and loss of synaptic function via chronic "excitotoxicity". ${ }^{14}$ Memantine, by acting as an uncompetitive NMDA receptor antagonist with moderate binding affinity, prevents the pathologic influx of calcium ions while allowing physiologic signals important for learning and memory processes. The interplay between cholinergic and glutamatergic pathways is complex, but it appears that excessive activation of glutamate receptors leads to degeneration of cholinergic cells in $\mathrm{AD} \cdot{ }^{13}$ Combined use of $\mathrm{ChEI}$ and memantine displays synergistic effects on spatial memory in mouse models of AD. . $^{15,16}$

\section{Pharmacokinetics}

One important step in the approval of the FDC was to establish its bioequivalence to coadministered memantine ER and donepezil. A Phase I open-label crossover study was performed in healthy men and women aged $18-45$ years. ${ }^{17}$ For memantine, coadministration resulted in a time to maximum plasma concentration of 14 vs 24 hours when administered as an FDC. The difference was not statistically significant $(P=0.27)$. The two formulations were also bioequivalent based on nonsignificant differences in maximum plasma concentration $\left(C_{\max }\right)$ and area under the plasma concentration-time curve (area under the curve, AUC).

A second Phase I study determined whether the bioavailability of the FDC capsule was affected by food intake and whether the FDC capsule contents sprinkled on applesauce was bioequivalent to the intact FDC capsule. ${ }^{17}$ In the threeperiod crossover study, bioequivalence was seen with the FDC capsule while fasting vs after a high-fat meal as well as between the intact FDC capsule while fasting and the capsule contents sprinkled on applesauce.

A previous open-label study in healthy men and women aged 18-35 years assessed the interaction between memantine IR and donepezil. ${ }^{18}$ In this study, the absorption of memantine or donepezil was not significantly affected during coadministration when compared with individual administration. The mean percent maximum inhibition of acetylcholinesterase activity in red blood cells was also not significantly different with donepezil alone vs donepezil combined with a single dose of memantine $(77.8 \%$ vs $81.1 \%$, respectively). While donepezil is metabolized primarily by 
CYP450, memantine does not appear to significantly interact with these enzymes.

By itself, memantine has a half-life of approximately 70 hours at steady state, which is achieved after 2 weeks of therapy. ${ }^{19}$ When compared with $10 \mathrm{mg}$ twice-daily memantine IR, $28 \mathrm{mg}$ once-daily memantine ER reportedly displays a $48 \%$ higher $C_{\max }$ and 33\% higher $\mathrm{AUC}_{0-24}{ }^{19,20}$ Memantine displays linear pharmacokinetics over the therapeutic dose range and is excreted mostly unchanged in urine.

Donepezil displays linear pharmacokinetics over the dose range of 1-10 $\mathrm{mg}$, has an elimination half-life of about 70 hours, and reaches a steady state within 15 days. ${ }^{19}$ Donepezil is excreted in the urine intact and extensively metabolized to four major and several other minor metabolites by the CYP450 enzymes 2D6 and 3A4.

\section{Dosing}

The FDC capsules originally were approved for two strengths, either a combination of $28 \mathrm{mg}$ memantine ER and $10 \mathrm{mg}$ donepezil or $14 \mathrm{mg}$ memantine ER and $10 \mathrm{mg}$ of donepezil (Table 1). ${ }^{19}$ On the basis of the package insert, the 28/10 mg FDC can be used in patients who are stabilized on the combination of memantine (10 mg twice daily or $28 \mathrm{mg}$ ER once daily) and donepezil $10 \mathrm{mg}$. Patients with severe renal impairment stabilized on a combination of memantine ( $5 \mathrm{mg}$ twice daily or $14 \mathrm{mg}$ ER once daily) and donepezil $10 \mathrm{mg}$ can be switched to the 14/10 mg FDC. In July 2016, the FDA approved an expanded label for the FDC. Patients stabilized on donepezil $10 \mathrm{mg} / \mathrm{d}$ can now start directly with a $7 \mathrm{mg}$ memantine ER and $10 \mathrm{mg}$ donepezil capsule. This dosage can be increased weekly in $7 \mathrm{mg}$ increments of memantine ER first to the $14 / 10 \mathrm{mg}$ tablet, then to the $21 / 10 \mathrm{mg}$ tablet, and finally to the $28 / 10 \mathrm{mg}$ tablet.

Donepezil is FDA approved for the treatment of mild, moderate, and severe AD. A dose range of 5-10 mg once daily is indicated for mild-to-moderate $\mathrm{AD}$ and may be administered as 5 or $10 \mathrm{mg}$ tablets or orally disintegrating tablets. In patients with moderate-to-severe $\mathrm{AD}$, approved formulations include the $10 \mathrm{mg}$ tablet, $10 \mathrm{mg}$ orally disintegrated tablet, and a $23 \mathrm{mg}$ tablet. Memantine is available in two forms, either immediate or ER. The IR version comes in either 5 or $10 \mathrm{mg}$ tablets or a $2 \mathrm{mg} / \mathrm{mL}$ oral solution. The recommended effective dose is $20 \mathrm{mg} / \mathrm{d}$, taken as a $10 \mathrm{mg}$ tablet twice daily. The memantine ER capsule is started at a dose of $7 \mathrm{mg}$ once daily and titrated to a maintenance dose of $28 \mathrm{mg}$ once daily.

\section{Efficacy MEM-MD-50}

The FDA did not require any additional efficacy studies prior to the approval of the FDC. Only one efficacy trial was previously reviewed during the approval process for memantine ER. This study, entitled MEM-MD-50, was a 24-week randomized controlled trial (RCT) comparing memantine ER $28 \mathrm{mg}$ once daily to placebo in community-dwelling participants with moderate-to-severe AD receiving a stable dose of a ChEI (Table 2). ${ }^{21}$ This study was conducted in four countries (the United States, Argentina, Chile, and Mexico), and enrolled patients with a baseline Mini-Mental State Examination (MMSE) score 3-14 who were on a stable dose of either galantamine, rivastigmine, or donepezil for at least 3 months. The primary efficacy measures were change from

Table I US Food and Drug Administration approved therapies for the treatment of moderate-to-severe Alzheimer's disease

\begin{tabular}{|c|c|c|c|c|}
\hline Drug & Formulations & $\begin{array}{l}\text { Dosing } \\
\text { options }\end{array}$ & $\begin{array}{l}\text { FDA recommended dosing } \\
\text { for moderate AD }\end{array}$ & $\begin{array}{l}\text { FDA recommended } \\
\text { dosing for severe AD }\end{array}$ \\
\hline \multirow[t]{2}{*}{ Donepezil } & Tablet & $5,10,23 \mathrm{mg}$ & 5,10 , and $23 \mathrm{mg}$ once daily & 10 and $23 \mathrm{mg}$ once daily \\
\hline & Orally disintegrating tablet & $5,10 \mathrm{mg}$ & & \\
\hline \multirow[t]{3}{*}{ Rivastigmine } & Capsule & $1.5,3,4.5,6 \mathrm{mg}$ & $6-12 \mathrm{mg} / \mathrm{d}$ administered as twice daily & Not approved for severe $A D$ \\
\hline & Oral solution & $2 \mathrm{mg} / \mathrm{mL}$ & & \\
\hline & Transdermal patch & $4.6,9.5,13.3 \mathrm{mg} / 24 \mathrm{~h}$ & 9.5 or $13.3 \mathrm{mg} / 24 \mathrm{~h}$ once daily & $13.3 \mathrm{mg} / 24 \mathrm{~h}$ once daily \\
\hline \multirow[t]{3}{*}{ Galantamine } & Extended-release capsule & $8,16,24 \mathrm{mg}$ & 16-24 mg once daily & Not approved for severe $A D$ \\
\hline & Tablet & $4,8,12 \mathrm{mg}$ & $16-24 \mathrm{mg} / \mathrm{d}$ administered as twice daily & \\
\hline & Oral solution & $4 \mathrm{mg} / \mathrm{mL}$ & & \\
\hline \multirow[t]{3}{*}{ Memantine } & Extended-release capsule & $7,14,21,28 \mathrm{mg}$ & $28 \mathrm{mg}$ once daily & $28 \mathrm{mg}$ once daily \\
\hline & Tablet & $5,10 \mathrm{mg}$ & $20 \mathrm{mg} / \mathrm{d}$ administered as twice daily & $20 \mathrm{mg} / \mathrm{d}$ administered as twice daily \\
\hline & Oral solution & $2 \mathrm{mg} / \mathrm{mL}$ & & \\
\hline \multirow[t]{4}{*}{$\begin{array}{l}\text { Memantine/donepezil } \\
\text { FDC }\end{array}$} & $\begin{array}{l}\text { Memantine extended- } \\
\text { release/donepezil capsule }\end{array}$ & $7 / 10 \mathrm{mg}$ & $\begin{array}{l}28 \mathrm{mg} \text { memantine/ } \mathrm{l} 0 \mathrm{mg} \text { donepezil } \\
\text { once daily }\end{array}$ & $\begin{array}{l}28 \mathrm{mg} \text { memantine/ } \mathrm{l} 0 \mathrm{mg} \text { donepezil } \\
\text { once daily }\end{array}$ \\
\hline & & $14 / 10 \mathrm{mg}$ & & \\
\hline & & $2 \mathrm{I} / 10 \mathrm{mg}$ & & \\
\hline & & $28 / 10 \mathrm{mg}$ & & \\
\hline
\end{tabular}

Abbreviations: $A D$, Alzheimer's disease; FDC, fixed-dose combination. 
Table 2 Summary of the major randomized controlled trials involving addition of memantine to patients with AD already on a stable dose of cholinesterase inhibitor

\begin{tabular}{|c|c|c|c|c|}
\hline Study & MEM-MD-02 ${ }^{34}$ & MEM-MD- $12^{35}$ & MEM-MD-5021 & DOMINO-AD ${ }^{39}$ \\
\hline Treatment & $\begin{array}{l}\text { Memantine IR ( } 20 \mathrm{mg} / \text { day }) \\
\text { vs placebo }\end{array}$ & $\begin{array}{l}\text { Memantine IR ( } 20 \mathrm{mg} / \text { day }) \\
\text { vs placebo }\end{array}$ & $\begin{array}{l}\text { Memantine ER } 28 \mathrm{mg} \text { once } \\
\text { daily vs placebo }\end{array}$ & $\begin{array}{l}\text { Memantine IR ( } 20 \mathrm{mg} / \text { day }) \text { vs } \\
\text { placebo when donepezil was } \\
\text { continued }\end{array}$ \\
\hline Population & $\begin{array}{l}404 \text { participants with } \\
\text { moderate-to-severe AD } \\
\text { (mean MMSE I0.I) on stable } \\
\text { dose of donepezil }\end{array}$ & $\begin{array}{l}433 \text { participants with mild- } \\
\text { to-moderate AD (mean } \\
\text { MMSE 16.8) on stable dose } \\
\text { of ChEl }\end{array}$ & $\begin{array}{l}677 \text { participants with } \\
\text { moderate-to-severe AD } \\
\text { (mean MMSE 10.8) on stable } \\
\text { dose of ChEl }\end{array}$ & $\begin{array}{l}295 \text { participants with } \\
\text { moderate-to-severe AD } \\
\text { (mean MMSE 9.0) on stable } \\
\text { dose of donepezil }\end{array}$ \\
\hline Duration & 24 weeks & 24 weeks & 24 weeks & 52 weeks \\
\hline Cognitive scale & $\begin{array}{l}\text { Significantly favored } \\
\text { memantine IR on SIB }\end{array}$ & $\begin{array}{l}\text { No significant difference on } \\
\text { ADAS-Cog }\end{array}$ & $\begin{array}{l}\text { Significantly favored } \\
\text { memantine ER on } S^{\text {a }}{ }^{a}\end{array}$ & $\begin{array}{l}\text { No significant difference on } \\
\text { sMMSE }^{\mathrm{a}}\end{array}$ \\
\hline Global rating scale & $\begin{array}{l}\text { Significantly favored } \\
\text { memantine IR on CIBIC-plus }\end{array}$ & $\begin{array}{l}\text { No significant difference on } \\
\text { CIBIC-plus }{ }^{\mathrm{a}}\end{array}$ & $\begin{array}{l}\text { Significantly favored } \\
\text { memantine ER on CIBIC-plus }{ }^{\mathrm{a}}\end{array}$ & \\
\hline Functional scale & $\begin{array}{l}\text { Significantly favored } \\
\text { memantine IR on ADCS- } \\
\text { ADL-19a }\end{array}$ & $\begin{array}{l}\text { No significant difference on } \\
\text { ADCS-ADL- } 23\end{array}$ & $\begin{array}{l}\text { No significant difference on } \\
\text { ADCS-ADL-19 }\end{array}$ & $\begin{array}{l}\text { No significant difference on } \\
\text { BADLS }^{\mathrm{a}}\end{array}$ \\
\hline Behavioral scale & $\begin{array}{l}\text { Significantly favored } \\
\text { memantine IR on NPI }\end{array}$ & $\begin{array}{l}\text { No significant difference } \\
\text { on NPI }\end{array}$ & $\begin{array}{l}\text { Significantly favored } \\
\text { memantine ER on NPI }\end{array}$ & $\begin{array}{l}\text { Significantly favored } \\
\text { memantine IR on NPI }\end{array}$ \\
\hline
\end{tabular}

Note: andicates primary efficacy endpoints.

Abbreviations: AD, Alzheimer's disease; ADCS-ADL-19, 19-item Alzheimer Disease Cooperative Study-Activities of Daily Living Inventory; ADCS-ADL-23, 23-item Alzheimer Disease Cooperative Study-Activities of Daily Living Inventory; BADLS, Bristol Activities of Daily Living Scale; ChEl, cholinesterase inhibitor; CIBIC-plus, Clinician's Interview-Based Impression of Change Plus Caregiver Input; ER, extended-release; IR, immediate-release; NPI, Neuropsychiatric Inventory; SIB, Severe Impairment Battery; sMMSE, Standardized Mini-Mental State Examination.

baseline in the Severe Impairment Battery (SIB) total score and the Clinician's Interview-Based Impression of Change Plus Caregiver Input (CIBIC-plus) score at week 24. The SIB is a 40-item, 100-point scale that measures cognition and is commonly used in clinical trials involving patients with moderate-to-severe AD because it is composed of simple one-step commands. ${ }^{22}$ Higher scores indicate less impairment. The CIBIC-plus utilizes a seven-point scale to assess a patient's global functioning, ranging from one (marked improvement) to seven (marked worsening). A score of 4 indicates no change. Secondary outcomes included the 19-item Alzheimer's Disease Cooperative Study-Activities of Daily Living Inventory (ADCS-ADL-19), a 19-item scale composed of a subset of questions from a 42 -item inventory that assesses functional ability based on activities such as eating, bathing, making conversation, and use of a telephone. The Neuropsychiatric Inventory (NPI), a scale assessing behavioral disturbances, and the Verbal Fluency Test (VFT), a task where patients name as many animals as they can in 60 seconds, were also included as secondary measures. Of the 677 patients randomized to receive placebo $(n=335)$ or memantine ER $(n=342), 81.2 \%$ and $79.8 \%$ of participants completed the trial, respectively. Almost $70 \%$ of participants were Hispanic. The treatment groups had been on ChEI therapy for an average duration ranging from 14.2 to 17.5 months with either donepezil, galantamine, or rivastigmine.
At week 24, memantine ER showed significant differences from placebo on both primary endpoints. Memantine ER was associated with a mean improvement of 2.7 points from baseline on the SIB compared with slight improvement with placebo $(0.3$ points, least squares mean difference $[\mathrm{LSMD}]=2.6$, $95 \%$ confidence interval $[\mathrm{CI}]=1.0,4.2)$. At week 24 , mean scores on the CIBIC-plus were 3.8 for memantine ER and 4.1 for placebo $(P=0.008)$. While there was no significant difference on the ADCS-ADL-19, memantine ER showed significant improvements on the NPI (LSMD $=-2.7,95 \%$ $\mathrm{CI}=-4.5,-0.8)$ and the VFT (LSMD $=0.5,95 \% \mathrm{CI}=0.2,0.9)$ compared with placebo. In a subgroup of donepezil-treated patients, a significant difference favoring memantine ER was seen on the SIB (LSMD of 3.2, $P=0.001)$, NPI ( $P=0.009)$, and VFT $(P<0.001)$ but not the ADCS-ADL-19 (LSMD $=0.1$, $P=0.894)$ or CIBIC-plus (LSMD $=0.2, P=0.165){ }^{23,24}$

The FDA also analyzed intercountry differences. ${ }^{23,25}$ While the mean baseline SIB scores were similar across the four countries, the mean differences from baseline on the SIB with memantine compared to placebo were more pronounced in the three foreign countries $(3.3,1.5,3.03)$ when compared with the United States (0.81). Treatment with memantine in the United States was associated with a slight worsening in total SIB score $(-0.12)$ compared with improvements on the SIB in the other countries $(3.53,5.02,2.87)$. However, in the United States, treatment with memantine $(\mathrm{n}=89)$ was still advantageous compared with placebo $(n=83)$ on the 
SIB ( -0.12 vs -0.93 , respectively). Treatment differences among the countries persisted after correcting for differences in demographics and baseline characteristics. The treatment effect on the CIBIC-plus was similar across the different countries. There was also no statistically significant treatment group-by-country interaction on the SIB or CIBICPlus. ${ }^{23}$ The FDA summary reviewer felt that the differences in treatment effects among countries were not unusual, and there were no irregularities found during site inspections conducted in Argentina. ${ }^{26}$

A number of post hoc analyses from this trial have also been performed. Treatment with memantine ER significantly improved certain SIB subscales associated with language, such as reading/writing and comprehension/repetition/ discourse, but not naming or functional communication score. ${ }^{27}$ Significant advantages were seen with memantine ER on the SIB domains of memory, language, attention, praxis, orientation, and construction. ${ }^{28}$ While treatment with memantine did not show a significant advantage on ADCS-ADL-19 total scores, significant improvements were seen on the items of eating, clearing the table, and finding belongings. ${ }^{29}$ Memantine ER was also superior to placebo in the proportion of participants achieving a clinically notable response, defined as $\geq 3$ point improvement on the SIB and ADCS-ADL-19 and endpoint score $\leq 3$ on the CIBIC-Plus ( $12.4 \%$ vs $7.4 \%$, $P=0.030$, number needed to treat $[\mathrm{NNT}]=20) .{ }^{30}$

Caregiver distress was assessed with the NPI Caregiver Distress Scale (NPI-D). This scale involves asking the caregiver how much emotional or psychological distress each of the 12 components on the NPI causes him or her. ${ }^{31}$ At week 24, scores numerically favored memantine ER over placebo treatment for 9 out of 12 items, with statistically significant results for agitation and nighttime behavior. ${ }^{32}$ The difference in total NPI-D score was not statistically significant (LSMD $=-1.07, P=0.069$ ).

While the FDA chose to approve memantine ER based on the efficacy data from this study, the European Medicines Agency decided against approval..$^{33}$ They questioned the clinical relevance of the drug given the small differences on the coprimary endpoints and the nonsignificant differences on the functional measure (ADCS-ADL-19). In addition, since no comparison studies were performed between memantine IR and memantine ER, the risk-to-benefit ratio could not be fully evaluated.

\section{MEM-MD-02 and MEM-MD- 12}

A few major studies have been performed using memantine IR in combination with ChEI therapy (Table 2). MEM-MD-02 was a 24-week RCT involving patients with moderateto-severe AD on a stable dose of donepezil..$^{34}$ Patients were randomized to either $20 \mathrm{mg}$ once-daily memantine (titrated up from $5 \mathrm{mg} / \mathrm{d}$ over 4 weeks; $\mathrm{n}=203$ ) or placebo $(\mathrm{n}=201)$. Inclusion criteria included an MMSE of 5-14 and ongoing ChEI therapy with donepezil for more than 6 months and at a stable dose of 5-10 mg/d for at least 3 months. Coprimary outcomes were the SIB and ADCS-ADL-19. At 24 weeks, significantly more patients in the memantine group completed the study compared to the placebo group ( $85.1 \%$ vs $74.6 \%$, $P=0.01)$. Memantine was superior to placebo on change from baseline to week 24 on SIB total score $(0.9$ vs -2.5 , $P<0.001)$ and ADCS-ADL-19 total score $(-3.4$ vs -2.0 , $P=0.03$ ). Memantine was also superior to placebo on some secondary efficacy measures, such as the CIBIC-plus, NPI, and the Behavioral Rating Scale for Geriatric Patients-care dependency subscale.

In another 24-week RCT entitled MEM-MD-12, addition of $20 \mathrm{mg}$ once-daily memantine to 433 patients with mild-to-moderate AD (MMSE scores of 10-22) on stable dose of ChEIs (donepezil, rivastigmine, or galantamine) was not significantly beneficial. ${ }^{35}$ No statistically significant difference was seen on the Alzheimer's Disease Assessment Scale-cognitive subscale or CIBIC-plus at the study's endpoint. The effect size on the Alzheimer's Disease Assessment Scale-cognitive subscale was 0.118 .

On the basis of the negative results of this study in mildto-moderate patients, a pooled analysis of MEM-MD-12 and MEM-MD-02 examined the effects of memantine IR therapy by stratifying patients according to baseline disease severity using only patients receiving donepezil $10 \mathrm{mg} / \mathrm{d}$ therapy. ${ }^{36,37}$ Subgroups were composed of patients treated with either memantine added to donepezil or placebo added to donepezil and with either moderate-to-severe AD (MMSE range 5-19) or moderate AD (MMSE range 10-19). From baseline to week 24, patients in the moderate-to-severe AD subgroup receiving memantine in addition to donepezil performed significantly better on measures of cognition, function, and global status compared with placebo treatment added to donepezil. Effect sizes were 0.36 for cognition, 0.21 for function, and 0.23 for global status. In the moderate subgroup, memantine was significantly advantageous with effect sizes of 0.28 for cognition, 0.21 for function, and 0.28 for global status. Patients in the moderate-tosevere and moderate subgroups receiving memantine also showed a significantly decreased rate of marked clinical worsening, defined as a decline of $\geq 4$ points on ADAS-Cog or $\geq 5$ points on SIB, plus any decline on ADCS-ADL-19 or 
ADCS-ADL-23 and CIBIC-plus. In the moderate subgroup, $11 / 185$ (5.9\%) patients receiving memantine displayed marked clinical worsening compared to $27 / 180(15.0 \%)$ patients receiving placebo in addition to donepezil (mean difference $=9.1 \%, P=0.006$ ).

A post hoc analysis of four clinical trials involving memantine in moderate-to-severe $\mathrm{AD}$, which included the MEM-MD-02 and MEM-MD-50 trials, presented data using an AUC analysis to identify cumulative benefits over time. ${ }^{38}$ Combination therapy with memantine and donepezil resulted in significantly greater AUC improvements over donepezil monotherapy alone on cognition (SIB; 67.4 vs 27.5, $P<0.01$ ), behavior (NPI; -74.3 vs $-27.2, P<0.01$ ), and global clinical status (CIBIC-plus; -2.1 vs $1.4, P<0.05$ ) but not on function (ADCS-ADL-19; 1.4 vs -9.5). In a four domain composite index, memantine and donepezil treatment resulted in a significantly greater improvement than donepezil monotherapy $(P=0.003)$. The benefit of combination therapy was found to be additive not synergistic compared to monotherapy with donepezil or memantine.

\section{DOMINO-AD}

The Donepezil and Memantine in Moderate-to-Severe Alzheimer's Disease (DOMINO-AD) study was an RCT designed to answer the question of whether or not community-dwelling patients in the moderate-to-severe stages of AD should continue donepezil therapy, discontinue donepezil therapy, or begin memantine therapy in addition to donepezil (Table 2). ${ }^{39}$ Inclusion criteria included a Standardized Mini-Mental State Examination (sMMSE) score between 5 and 13, continuous treatment with donepezil for at least 3 months, and treatment with $10 \mathrm{mg}$ donepezil for at least the previous 6 weeks. It was also required that the participant's prescribing clinician was considering a change in treatment at the time. Primary outcome measures included scores on the sMMSE (higher scores indicate better cognitive function) and the caregiver-rated Bristol Activities of Daily Living Scale (BADLS, higher scores indicate greater impairment). While an initial sample size of 800 was planned, the planned size was readjusted to 430 based on statistical reanalysis. However, difficulties with recruitment led to a final sample of 295 participants. The probability of withdrawal was significantly less in patients assigned to continue donepezil treatment compared to discontinuing donepezil treatment $(0.51,95 \% \mathrm{CI}=0.36,0.72)$. The dropout rate was fairly high among all groups, with $20 / 72$ in the discontinue donepezil add placebo group, $27 / 74$ in the discontinue donepezil add memantine group,
$34 / 73$ in the continue donepezil add placebo group, and $38 / 72$ in the continue donepezil add memantine group remaining at the study's endpoint of 52 weeks. Patients assigned to continue donepezil vs those who discontinued donepezil had significantly higher scores on the sMMSE (1.9 points, 95\% CI $=1.3,2.5)$ and significantly lower scores on the BADLS (3.0 points, 95\% CI $=1.8,4.3$ ) after 52 weeks. Patients assigned to receive memantine vs placebo showed significantly higher sMMSE scores ( $\mathrm{LSMD}=1.2,95 \% \mathrm{CI}=0.6,1.8)$ and lower BADLS scores $(\mathrm{LSMD}=1.5,95 \% \mathrm{CI}=0.3,2.8)$. These values were smaller than prespecified minimum clinically important differences for the sMMSE (1.4 points) and BADLS (3.5 points). No significant benefit was seen with adding memantine to donepezil compared to adding placebo to donepezil on either the MMSE (difference of 0.8 points; $95 \% \mathrm{CI}=-0.1$, $1.6 ; P=0.07$ ) or the BADLS (difference of -0.5 points; $95 \% \mathrm{CI}=-2.2,1.2 ; P=0.57)$. A significant benefit on the NPI of 5.1 points $(99 \% \mathrm{CI}=0.3-9.8, P=0.006)$ was seen with the addition of memantine to donepezil compared with adding placebo to donepezil.

The overall conclusion by the authors of this study was that there was no significant benefit of adding memantine to donepezil therapy based on a lack of significant heterogeneity in the efficacy of donepezil or memantine in the presence or absence of the other. A number of criticisms have been brought forth regarding this study, including the insufficient recruitment and high and unbalanced attrition rate. ${ }^{36,40}$ Interestingly, the data do show a significant advantage on the sMMSE but not the BADLS at week 30 with combination therapy compared to donepezil alone. This effect did not reach significance at week 52 . A reanalysis using different statistical models showed no evidence of a synergistic interaction between donepezil and memantine. However, there was evidence of a significant additive effect of combination therapy on the sMMSE and BADLS. ${ }^{41}$

A secondary and post hoc analysis of the DOMINO-AD study assessed the effect of donepezil and memantine treatment on nursing home placement. ${ }^{42}$ Over a 4-year period, $162(55 \%)$ patients were admitted to nursing homes. The prespecified outcome of time to nursing home placement when continuing vs discontinuing donepezil was significant in the stratified analysis $(P=0.022)$ but not significant in the unstratified analysis $(P=0.100)$. However, the hazard ratios were nonproportional $(P=0.01)$ since the effect of discontinuing donepezil changed over time. An analysis that was not prespecified showed that significantly more patients during the first year were admitted to nursing homes in the group 
that discontinued donepezil and added either placebo or memantine compared to the group that continued donepezil and added either memantine or placebo (hazard ratio $=2.09$, 95\% CI $=1.29,3.39$ ). The difference in probability of nursing home placement with discontinuing donepezil vs continuing donepezil was 0.17 (37\% vs $20 \%$, respectively) corresponding to an NNT of 5.88 patients for 12 months to prevent one nursing home placement. No significant difference was seen in nursing home placement with combination memantine and donepezil therapy compared to donepezil therapy alone. One important limitation of this study was that no information was collected about AD therapy use after the 52 week double-blind period, meaning that the patient's clinician could reinstitute any combination of drug therapy during the subsequent 3-year follow-up period after the initial 52-week endpoint.

\section{Combination therapy in long-term observational trials}

Support for the combination of memantine and donepezil has also been provided by long-term observational controlled studies (LTOCs). ${ }^{43}$ Given that long-term RCTs are difficult to perform, LTOCs provide additional clinical efficacy data in a real-life setting involving patients with multiple comorbidities and varying levels of treatment adherence.

In a study involving 382 participants with a mean follow-up period of 30 months and mean treatment duration of 22.5 months, patients receiving memantine and ChEI therapy showed lower rates of deterioration on measures of cognition (Information-Memory-Concentration subscale of the Blessed Dementia Scale) and function (Weintraub ADL Scale) compared to ChEI monotherapy. ${ }^{44}$ The effect sizes for combination vs ChEI monotherapy after 4 years were 0.49 on the cognitive scale $(P<0.001)$ and 0.73 on the functional scale $(P<0.001)$. The benefits of combination therapy over monotherapy increased over time.

In another observational study of 943 probable AD patients with a mean follow-up time of 62.3 months, patients who received ChEIs only were less likely to be admitted to a nursing home than untreated patients (relative hazard $=0.37$, $95 \% \mathrm{CI}=0.27,0.49) .{ }^{45}$ Importantly, a group of patients receiving ChEIs plus memantine were significantly less likely to be admitted to a nursing home vs patients receiving only ChEI (relative hazard $=0.29,95 \% \mathrm{CI}=0.11,0.72$ ). LTOCs do have some limitations. Assignment of drug therapy is often not random, meaning that factors such as baseline disease severity, duration of symptoms, behavioral symptoms, and comorbidities remain uncontrolled.

\section{Safety and tolerability}

Donepezil is fairly well tolerated in clinical trials and open-label extension trials. Common adverse events (AEs) include nausea, vomiting, diarrhea, muscle cramps, dizziness, fatigue, and anorexia. ${ }^{46}$ Common AEs with memantine that occurred at higher rates than placebo include dizziness (6.3\% vs $5.6 \%)$, headache $(5.2 \%$ vs $3.9 \%)$, constipation (4.6\% vs $2.6 \%)$, and somnolence (3.4\% vs $2.2 \%) .{ }^{47}$ Patients with moderate-to-severe $\mathrm{AD}$ receiving memantine reported fewer discontinuations due to AEs compared with placebo (OR $=0.80,95 \% \mathrm{CI}=0.59,1.09)$.

ChEIs as a whole have been associated with some potential serious AEs, such as increased frequency of hospital visits for syncope, bradycardia, and hip fracture. ${ }^{48,49} \mathrm{ChEIs}$ have also been associated with a $24 \%$ increased risk of clinically significant weight loss over a 1 -year period, defined as loss of 10 pounds or more $(\mathrm{HR}=1.23,95 \% \mathrm{CI}=1.07,1.41) .{ }^{50}$ In a meta-analysis of RCTs and extension studies, ChEI use was associated with increased risk of syncope (odds ratio $=1.53,95 \% \mathrm{CI}=1.02,2.30$ ), but not falls, fractures, or accidental injury. ${ }^{51}$ Memantine was associated with a significantly decreased rate of fracture $(\mathrm{OR}=0.21,95 \%$ $\mathrm{CI}=0.05,0.85)$ and no significant difference in falls, syncope, or accidental injury.

In the MEM-MD-50 study involving memantine ER, the incidence of treatment-emergent adverse events was similar between the two groups (63.9\% for placebo vs $62.8 \%$ for memantine ER). Discontinuations due to an AE were also similar between placebo (21/335 patients, 6.3\%) and memantine $(34 / 341$ patients, $9.9 \%)$ treatment. Adverse events that occurred in the memantine group at twice the frequency of the placebo group included dizziness (4.7\% vs 1.5\%), depression (3.2\% vs $1.5 \%$ ), weight increase (3.2\% vs $0.9 \%$ ), constipation $(2.9 \%$ vs $1.2 \%)$, and back pain (2.6\% vs $0.6 \%)$. Among AEs that led to treatment discontinuation, most were unlikely to be attributed to memantine therapy with the exception of dizziness ( 5 cases with memantine vs 0 cases for placebo). In the MEM-MD-02 study involving addition of memantine IR to stable donepezil therapy in moderate-to-severe AD, AEs with memantine treatment at a frequency of at least $5 \%$ and twice that of placebo included confusion ( $7.9 \%$ vs $2.0 \%)$ and headache $(6.4 \%$ vs $2.5 \%)$.

The safety of the memantine/donepezil combination was also assessed in a pooled analysis of 23 Phase III and IV studies. ${ }^{52}$ The overall frequency of AEs was similar between the memantine/donepezil and placebo/donepezil groups. In a pool of placebo-controlled studies of 24-weeks duration representing 983 patients, the proportion of patients withdrawing 
due to AEs was $7.4 \%$ with memantine/donepezil compared to $10.5 \%$ with placebo/donepezil.

A few open-label extension studies have been performed to further assess the tolerability of memantine ER. In a 28-week open-label extension study of MEM-MD-50, AEs that occurred at greater than $5 \%$ of patients included falls, urinary tract infections, dizziness, agitation, and insomnia (all occurred at a frequency less than 10\%). ${ }^{23}$ Another 52-week open-label extension study of two open-label trials involving memantine-ER was performed. ${ }^{53}$ Of the 66 patients who received at least one dose of memantine during the 52 weeks, common AEs included urinary tract infection (13.6\%), agitation (12.1\%), and aggression (10.6\%). AEs in six patients $(9.1 \%)$ were deemed to be related or possibly related to memantine treatment.

\section{Cost analysis}

The memantine ER and ChEI combination compared with ChEI monotherapy alone in patients with moderate-to-severe AD was evaluated from a cost-effectiveness perspective. ${ }^{54}$ A population was simulated based on the baseline characteristics from the MEM-MD-50 study. Disease progression was modeled for a period of 3 years based on predictive equations using changes in SIB, NPI, and ADCS-ADL-19 scores. A monthly cost of $\$ 282.82$ for the memantine ER/ChEI combination, \$26.96 for ChEI monotherapy, and \$21.36 for antipsychotics was used. The primary outcome was qualityadjusted life-years (QALYs) for patients and caregivers, total direct and societal costs, and incremental direct and total cost per QALY gained. At the end of the 3-year simulation, treatment with memantine ER and ChEI was associated with a savings of $\$ 18,355$ compared with ChEI monotherapy when factoring in total direct costs and cost associated with caregiver time. Memantine ER and ChEI therapy also resulted in an additional 0.12 QALYs for patients and caregivers combined. Patients receiving the combination spent an average of 4 months longer living in the community. This delay in entering institutional care was the major driving force for cost savings with combination therapy. Patients receiving the combination therapy also spent less time in the severe stages of AD (3.64 vs 5.94 months for ChEI monotherapy over the 3-year period).

Multiple economic analyses have been performed with combination memantine IR and ChEI compared to ChEI monotherapy. ${ }^{55-57}$ Using data from MEM-MD-02, therapy with memantine and donepezil vs donepezil alone reduced total lifetime costs of formal and informal services by $\$ 242 .{ }^{55}$ The smaller savings compared with the previous study mentioned is possibly due to different assumptions of time in institutional facilities. In the lifetime time horizon, the number of months in an institution was estimated at 44.59 for donepezil and 44.32 for memantine/donepezil. In the previous study, the difference in the mean amount of time spent in an institution over the 3-year period was more substantial, with an estimated 13.14 months for ChEI monotherapy and 9.15 months for memantine ER/ChEI combination. ${ }^{54}$

In another study using data from the LTOC study discussed earlier modeled over a time horizon of 7 years, combination memantine and ChEI was associated with a mean time to nursing home admission of 5.54 years compared to 4.57 years with ChEI monotherapy. ${ }^{45,56}$ The incremental gain in QALYs for combination therapy as compared with ChEIs alone was 0.25 (3.37 vs 3.11, respectively). Cost savings with combination therapy was $€ 8,341$ from a health care system perspective (direct medical costs such as medical visits and hospitalizations) and $€ 3,318$ from a societal perspective (all direct and indirect costs including informal help) compared to ChEI monotherapy.

\section{Place of an FDC of memantine ER and donepezil in AD therapy}

On the basis of the pivotal MEM-MD-50 trial, the FDA approved the use of memantine ER in 2010. The efficacy data of this trial along with pharmacokinetic data from two Phase I trials resulted in the approval of an FDC of memantine ER and donepezil in 2014. The European Medicines Agency has ruled against approval of both memantine ER and a combination of memantine $20 \mathrm{mg}$ IR and donepezil $10 \mathrm{mg}$.

When patients are initiated on combination therapy for $\mathrm{AD}$, treatment options include the FDC of memantine ER and donepezil, individual memantine ER and donepezil, or individual memantine IR and donepezil (both available in generic forms). One can also combine the ChEIs rivastigmine or galantamine with memantine ER or IR. The primary advantages of using the higher cost FDC compared to generic versions are a simplified treatment regimen (once-daily capsule) and ability to sprinkle the capsule on applesauce. These two factors may increase treatment adherence, treatment persistence, and reduce caregiver burden. Greater persistence with treatment does appear to be an important factor in slowing the rate of cognitive, functional, and global clinical decline. In an LTOC involving 641 patients with $\mathrm{AD}$ (baseline mean MMSE of 19.5) and a mean follow-up time of 3 years (range 0.8-13.4 years), patients with a higher persistency index (defined as total years of drug use divided by total years of disease symptoms) showed significantly slower rates of decline on cognitive, functional, and global measures. ${ }^{58}$ These effects were cumulative over time. Thus, if the FDC could increase 
treatment persistence, the added cost may be justified from both an economic perspective (eg, reducing admission to nursing homes) and a social perspective (eg, reducing caregiver burden and increasing patient quality of life).

With regard to the effect of simplifying treatment regimen on treatment adherence, in a meta-analysis of nine studies involving an FDC in the treatment of tuberculosis, hypertension, HIV disease, and diabetes, the use of an FDC resulted in a $26 \%$ decrease in the risk of noncompliance compared with freedrug components (relative risk $=0.74,95 \%$ CI $0.69-0.80$ ).$^{59} \mathrm{In}$ another study of FDC delivery of aspirin, statin, and two blood pressure-lowering agents vs usual care, the FDC group showed significantly improved adherence ( $86 \%$ vs $65 \%$, relative risk of being adherent $=1.33,95 \% \mathrm{CI}=1.26-1.41) .{ }^{60}$

The evidence regarding the effect of simplifying treatment regimens on patient adherence and persistence with $\mathrm{AD}$ therapy is mixed. The estimated rate of adherence to AD therapies is in the range of $34 \%-94 \%$, with a discontinuation rate for ChEIs ranging from $40 \%$ to $65 \%$ after 1 year and up to $90 \%$ after $2-3$ years. ${ }^{61,62}$ In a claims analysis of 3,091 patients with $\mathrm{AD}$ new to oral AD therapy, only $58 \%$ were found to be adherent to oral therapy and $40 \%$ discontinued their oral AD medication within the 1-year follow-up period. ${ }^{63}$ Interestingly, greater overall pill burden was associated with an increased odds of adherence (odds ratio $=1.19,95 \%$ CI $1.16,1.22$ ). The authors felt this might be due to an increase in caregiver support as medication regimens become more complex. Another study comparing the adherence of transdermal rivastigmine to oral donepezil found no significant difference in treatment adherence between patients with high pill burden vs low pill burden. ${ }^{64}$ With regard to treatment persistence, three studies have failed to find a significant association between higher pill burden and treatment persistence. ${ }^{65-67}$ However, adherence to the rivastigmine patch was significantly higher when compared with donepezil, suggesting that the simplified regimen of applying a patch once a day increases compliance when compared to multiple pill administrations. ${ }^{64}$ In addition, an observational database study found that 1-year treatment persistence was significantly greater with galantamine ER compared to galantamine IR ( $54 \%$ vs $44 \%$ ), although the total number of days of therapy was not significant (293 vs 286, respectively). ${ }^{62}$ Unfortunately, the comparison between these two versions of galantamine did not involve the same time period because galantamine IR was discontinued and replaced by galantamine ER in Canada. This study, which was performed prior to the approval of the rivastigmine patch, found that rivastigmine had the lowest rate of treatment persistence, which may be related to its twice-daily dosing compared to the once-daily galantamine ER and donepezil. A significant difference between duration of treatment was seen between galantamine ER and rivastigmine (292.5 vs 272.1 days, respectively; $P=0.0265$ ). Ultimately, the intuitive notion that reducing pill burden and simplifying treatment regimens would significantly improve adherence and persistence with treatment is not supported by a substantial and convincing body of evidence.

The ability of the FDC to be opened up and sprinkled on applesauce is another advantage given that dysphagia is a common problem in patients with advanced $\mathrm{AD}$, with an estimated prevalence between $7 \%$ and $44 \% .{ }^{68}$ Difficulty swallowing medications does appear to affect treatment adherence. In a survey involving 675 patients and 117 caregivers, $69 \%$ admitted to not taking a tablet or capsule because it was hard to swallow. ${ }^{69}$ In another study using a semistructured questionnaire of primary care patients aged 18 years and older, $47.3 \%$ of patients with ongoing or past difficulties with swallowing pills reported that these difficulties impaired their quality of daily life, with $12.1 \%$ of patients rating the difficulties as "extreme." " Swallowing difficulties led to self-reported intentional nonadherence in $22.8 \%$ of patients. Direct evidence that dysphagia affects treatment persistence specifically in patients with AD is sparse. One study involving the switch from oral donepezil to the rivastigmine transdermal patch found no statistically significant advantage of the patch in treatment persistence after one year for patients with dysphagia at baseline (53.9\% for rivastigmine vs $63.1 \%$ for donepezil, $P=0.1732)$. ${ }^{64}$ However, the number of patients with dysphagia at baseline was only 34 .

Memantine and donepezil are available in a variety of forms. The most common method of coping with difficulty swallowing oral tablets is to crush or split them. ${ }^{71,72}$ While the memantine ER capsule alone can be sprinkled on applesauce, donepezil $23 \mathrm{mg}$ tablets should not be crushed according to the package insert. No recommendation is made in the package inserts regarding crushing the donepezil 5 and 10 mg tablets or memantine 5 and $10 \mathrm{mg}$ tablets. Other methods include using orally disintegrating tablets or oral solutions. A generic orally disintegrating tablet is available for donepezil but not memantine. Memantine IR does come in an oral solution, but this is fairly expensive.

The economic analysis showing that the FDC ultimately results in cost savings over ChEI monotherapy despite a higher cost of therapy is reassuring. The major cost savings benefits appear to come from delaying institutionalization. The probability of institutionalization can be estimated in a number of ways, with most studies building a model that adjusts for baseline scores on cognitive or global 
measures. ${ }^{73,74}$ These probabilities are then entered into the simulation model to determine costs associated with treatment. Since combination therapy delays the rate of cognitive decline in clinical trials, these models provide indirect evidence for a cost savings benefit of combination therapy because according to the model the delay in cognitive decline would delay institutionalization. The actual evidence that combination therapy delays nursing home placement compared to monotherapy predominantly comes from one LTOC study. ${ }^{45}$ However, the DOMINO-AD study did not find a significant effect of combination therapy on delaying nursing home admission compared to monotherapy. ${ }^{42}$ The limitations of both LTOCs and the DOMINO-AD study must be kept in mind and ultimately make it difficult to come to a definitive conclusion at this time. ${ }^{75}$ More definitive studies that demonstrate combination therapy delays admission to nursing homes would be important as delay in nursing home placement has been ranked by patients as an important metric in quality of life and would lower economic costs. ${ }^{76}$

On an individual level, factors associated with a significantly higher probability of nursing home placement include one or more difficult behaviors, one or more dependencies in ADLs, and MMSE scores $\leq 20 .{ }^{77,78}$ With regard to ADLs, no significant difference was seen on the ADCS-ADL-19 scale between the two groups in the MEM-MD-50 trial. Statistical significance was reached in the MEM-MD-02 trial with memantine IR on the ADCS-ADL-19, and a pooled analysis of MEMMD-50 and MEM-MD-02 reported significant advantages of combination therapy over monotherapy in the domains of basic ADLs, simple praxis, and praxis items requiring visuo-spatial and memory skills. ${ }^{79}$ With regard to behavioral symptoms, memantine ER therapy compared with placebo significantly improved behavioral symptoms in the MEM-MD-50 study as measured by NPI total score and in the individual domains of agitation/aggression, irritability/lability, nighttime behavior, and delusions. ${ }^{21}$ Controlling these symptoms may play an important role in delaying nursing home admission.

One economic analysis that has not been performed is the comparison of memantine ER and memantine IR in combination with ChEIs since no studies have been performed comparing the two drugs. The patent exclusivity period for memantine IR tablets expired in July 2015, meaning that generic memantine IR is now available in the US. In 2014, Forest Pharmaceuticals planned to discontinue memantine IR tablets and only produce memantine ER, which retains patent exclusivity until 2029. An antitrust lawsuit was subsequently filed by the State of New York. The primary argument made was that if the IR version were discontinued, patients would be required to switch to the ER version. This may have dissuaded manufacturers from developing the generic IR tablets since most patients would have already been on a stable dose of the ER capsules for several months. If generic IR versions were to then become available in 2015, patients would have had to switch twice between 2014 and 2015, first to the ER capsules and then back to the generic IR tablets. The courts ruled in favor of the State, citing that the discontinuation of IR tablets violates parts of the Sherman antitrust act.$^{80}$ In August 2015, a generic version of memantine IR tablets was approved by the FDA. ${ }^{81}$ While the $C_{\max }$ and $\mathrm{AUC}_{0-24}$ are $48 \%$ and $33 \%$ higher, respectively, for $28 \mathrm{mg}$ memantine ER compared to $20 \mathrm{mg} / \mathrm{d}$ memantine IR, the clinical impact of these pharmacokinetic properties is not known since it has not been studied in clinical trials. Thus, $20 \mathrm{mg} / \mathrm{d}$ memantine IR given as $10 \mathrm{mg}$ tablets twice daily and the $28 \mathrm{mg}$ memantine ER component of the FDC are considered equivalent.

Overall, the evidence suggests that combination therapy with memantine and donepezil does provide significant advantages across multiple domains compared with ChEI monotherapy. Patients who may particularly benefit from an FDC of memantine ER and donepezil include those with significant dysphagia, a history of nonadherence, and limited caregiver interaction. However, there does not appear to be compelling, high-quality evidence that an FDC would substantially improve clinical outcomes over lower cost regimens, such as generic donepezil and memantine IR. Whether or not the added cost of the FDC is justified will likely be made on a case-by-case basis.

\section{Disclosures}

GT Grossberg serves as a consultant/speaker for Acadia, Accera, Actavis/Allergan, Avanir, Baxter, Daiichi Sankyo, Forest, GE, Genentech, Lundbeck, Novartis, Otsuka, Roche, and Takeda. GT Grossberg's department has received research support from Accera, Baxter, Forest/Actavis/Allergan, Janssen, Novartis, and Noven. GT Grossberg serves on safety monitoring boards for EryDel, Merck, and Newron. The authors report no other conflicts of interest in this work.

\section{References}

1. Alzheimer's Association. 2016 Alzheimer's disease facts and figures. Alzheimers Dement. 2016;12(4):459-509.

2. Alzheimer's Disease International. World Alzheimer report 2015: the global impact of dementia. 2015. Available from: https://www.alz.co.uk/ research/WorldAlzheimerReport2015.pdf. Accessed Aug 13, 2016.

3. Hurd MD, Martorell P, Delavande A, Mullen KJ, Langa KM. Monetary costs of dementia in the United States. $N$ Engl J Med. 2013;368(14): 1326-1334.

4. Gauthier S, Molinuevo JL. Benefits of combined cholinesterase inhibitor and memantine treatment in moderate-severe Alzheimer's disease. Alzheimers Dement. 2013;9(3):326-331. 
5. Atri A, Molinuevo JL, Lemming O, Wirth Y, Pulte I, Wilkinson D. Memantine in patients with Alzheimer's disease receiving donepezil: new analyses of efficacy and safety for combination therapy. Alzheimers Res Ther. 2013;5(1):6.

6. Matsunaga S, Kishi T, Iwata N. Combination therapy with cholinesterase inhibitors and memantine for Alzheimer's disease: a systematic review and meta-analysis. Int J Neuropsychopharmacol. 2015;18(5).

7. Farrimond LE, Roberts E, McShane R. Memantine and cholinesterase inhibitor combination therapy for Alzheimer's disease: a systematic review. BMJ Open. 2012;2(3).

8. National Institute for Health and Clinical Excellence. Donepezil, galantamine, rivastigmine and memantine for the treatment of Alzheimer's disease. NICE Technology Appraisal Guidance 217; 2011.

9. Schmidt R, Hofer E, Bouwman FH, et al. EFNS-ENS/EAN guideline on concomitant use of cholinesterase inhibitors and memantine in moderate to severe Alzheimer's disease. Eur J Neurol. 2015;22(6): 889-898.

10. Namenda XR (memantine hydrochloride) drug approval package. US Food and Drug Administration. 2010. Available from: https://www. accessdata.fda.gov/drugsatfda_docs/nda/2010/022525s000_namenda_ xr_toc.cfm. Accessed May 17, 2016.

11. Namzaric (memantine hydrochloride extended-release/donepezil hydrochloride) capsules. US Food and Drug Administration. 2014 Available from: https://www.accessdata.fda.gov/drugsatfda_docs/ nda/2014/206439Orig1s000TOC.cfm. Accessed May 17, 2016.

12. Krstic D, Knuesel I. Deciphering the mechanism underlying late-onset Alzheimer disease. Nat Rev Neurol. 2013;9(1):25-34.

13. Parsons CG, Danysz W, Dekundy A, Pulte I. Memantine and cholinesterase inhibitors: complementary mechanisms in the treatment of Alzheimer's disease. Neurotox Res. 2013;24(3):358-369.

14. Danysz W, Parsons CG. Alzheimer's disease, beta-amyloid, glutamate, NMDA receptors and memantine - searching for the connections. Br J Pharmacol. 2012;167(2):324-352.

15. Neumeister KL, Riepe MW. Synergistic effects of antidementia drugs on spatial learning and recall in the APP23 transgenic mouse model of Alzheimer's disease. J Alzheimers Dis. 2012;30(2):245-251.

16. Martinez-Coria H, Green KN, Billings LM, et al. Memantine improves cognition and reduces Alzheimer's-like neuropathology in transgenic mice. Am J Pathol. 2010;176(2):870-880.

17. Boinpally R, Chen L, Zukin SR, McClure N, Hofbauer RK, Periclou A. A novel once-daily fixed-dose combination of memantine extended release and donepezil for the treatment of moderate to severe Alzheimer's disease: two phase I studies in healthy volunteers. Clin Drug Investig. 2015;35(7):427-435.

18. Periclou AP, Ventura D, Sherman T, Rao N, Abramowitz WT. Lack of pharmacokinetic or pharmacodynamic interaction between memantine and donepezil. Ann Pharmacother. 2004;38(9):1389-1394.

19. Namzaric (memantine hydrochloride extended-release and donepezil hydrochloride) [package insert]. Cincinnati, OH: Forest Pharmaceuticals, Inc; 2016.

20. Lam S, Smith C, Gomolin IH. Memantine standard tablet and extendedrelease dosing considerations: a pharmacokinetic analysis. $J$ Am Geriatr Soc. 2015;63(2):383-384.

21. Grossberg GT, Manes F, Allegri RF, et al. The safety, tolerability, and efficacy of once-daily memantine $(28 \mathrm{mg})$ : a multinational, randomized, double-blind, placebo-controlled trial in patients with moderateto-severe Alzheimer's disease taking cholinesterase inhibitors. CNS Drugs. 2013;27(6):469-478.

22. Schmitt FA, Ashford W, Ernesto C, et al. The severe impairment battery: concurrent validity and the assessment of longitudinal change in Alzheimer's disease. The Alzheimer's Disease Cooperative Study. Alzheimer Dis Assoc Disord. 1997;11(Suppl 2):S51-S56.

23. Center for Drug Evaluation and Research. Review and evaluation of clinical data (Medical review). US Food and Drug Administration. 2010. Available from: https://www.accessdata.fda.gov/ drugsatfda_docs/nda/2010/022525Orig1 s000MedR.pdf. Accessed Aug 13, 2016.
24. Grossberg G, Alva G, Hendrix S, Hofbauer R, Pejovic V, Graham SM. Efficacy and tolerability of memantine extended release added to stable donepezil regimen in individuals with moderate to severe Alzheimer's disease: subset analysis of a randomized clinical trial. Alzheimers Dement. 2014;10(Suppl 4):P450.

25. Center for Drug Evaluation and Research. Review and evaluation of clinical data (statistical review and evaluation). US Food and Drug Administration. 2010. Available from: https://www.accessdata.fda. gov/drugsatfda_docs/nda/2010/022525Orig1s000StatR.pdf. Accessed Aug 13, 2016.

26. Center for Drug Evaluation and Research. Summary review. US Food and Drug Administration. 2010. Available from: https://www.accessdata.fda.gov/drugsatfda_docs/nda/2010/022525Orig1s000SumR.pdf. Accessed Aug 13, 2016.

27. Tocco M, Hendrix S, Miller M, Pejovic V, Graham S. Effects of extended-release memantine ( $28 \mathrm{mg}$, once daily) on language and communication abilities in a randomized trial of patients with moderate-to-severe Alzheimer's disease. Alzheimers Dement. 2012; 8(Suppl 4):P589.

28. Tocco M, Hendrix S, Miller M, Pejovic V, Graham S. Effects of extended-release memantine $(28 \mathrm{mg} /$ day $)$ on cognitive domains in patients with moderate to severe Alzheimer's disease: post hoc analysis of a randomized trial. Alzheimers Dement. 2011;7(Suppl 4):S784-S785.

29. Tocco M, Hendrix S, Miller M, Pejovic V, Graham S. Effects of extended-release memantine $(28 \mathrm{mg} /$ day $)$ on activities of daily living in patients with moderate to severe alzheimer's disease: post hoc factor analysis of a randomized trial. Alzheimers Dement. 2011; 7(Suppl 4):S790-S791.

30. Graham S, Hendrix S, Miller M. Response across multiple outcome measures in a randomized trial of extended-release memantine $(28 \mathrm{mg}$, once daily) in patients with moderate-to-severe Alzheimer's disease. Alzheimers Dement. 2012;8(Suppl 4):S591.

31. Kaufer DI, Cummings JL, Christine D, et al. Assessing the impact of neuropsychiatric symptoms in Alzheimer's disease: the Neuropsychiatric Inventory Caregiver Distress Scale. J Am Geriatr Soc. 1998;46(2): 210-215.

32. Atri A, Hendrix S, Ellison N, Pejović V, Otcheretko V. Caregiver distress related to neuropsychiatric symptoms is reduced with extendedrelease memantine-cholinesterase inhibitor combination in patients with moderate to severe Alzheimer's disease. Alzheimers Dement. 2015;11(Suppl 7):P749-P750.

33. Withdrawal assessment report: memantine FGK. European Medicines Agency. 2012. Available from: http://www.ema.europa.eu/docs/ en_GB/document_library/Application_withdrawal_assessment_report/ human/002687/WC500141943.pdf. Accessed May 17, 2016.

34. Tariot PN, Farlow MR, Grossberg GT, et al. Memantine treatment in patients with moderate to severe Alzheimer disease already receiving donepezil: a randomized controlled trial. JAMA. 2004;291(3):317-324.

35. Porsteinsson AP, Grossberg GT, Mintzer J, Olin JT, Memantine MEMMDSG. Memantine treatment in patients with mild to moderate Alzheimer's disease already receiving a cholinesterase inhibitor: a randomized, double-blind, placebo-controlled trial. Curr Alzheimer Res. 2008;5(1):83-89.

36. Atri A, Molinuevo JL, Lemming O, Wirth Y, Pulte I, Wilkinson D. Memantine in patients with Alzheimer's disease receiving donepezil: new analyses of efficacy and safety for combination therapy. Alzheimers Res Ther. 2013;5(1):6.

37. Molinuevo JL, Lemming O. Effects of memantine in patients with moderate Alzheimer's disease receiving stable doses of donepezil. Alzheimers Dement. 2012;8(Suppl 4):P601.

38. Atri A, Hendrix SB, Pejovic V, et al. Cumulative, additive benefits of memantine-donepezil combination over component monotherapies in moderate to severe Alzheimer's dementia: a pooled area under the curve analysis. Alzheimers Res Ther. 2015;7(1):28.

39. Howard R, McShane R, Lindesay J, et al. Donepezil and memantine for moderate-to-severe Alzheimer's disease. N Engl J Med. 2012; 366(10):893-903. 
40. Shaw G. Two drugs are not better than one for treating moderate to severe Alzheimer Disease, British investigators report: why some US neurologists don't agree. Neurology Today [serial on the Internet]. 2012;12(8):12-13. Available from: http://journals.lww.com/ neurotodayonline/Fulltext/2012/04190/Two_Drugs_Are_Not_Better_Than_One_for_Treating.10.aspx. Accessed May 17, 2016.

41. Hendrix S, Ellison N, Stanworth S, Otcheretko V, Tariot PN. Post hoc evidence for an additive effect of memantine and donepezil: consistent findings from DOMINO-AD study and memantine clinical trial program. J Prev Alzheimers Dis. 2015;2(3):165-171.

42. Howard R, McShane R, Lindesay J, et al. Nursing home placement in the Donepezil and Memantine in Moderate to Severe Alzheimer's Disease (DOMINO-AD) trial: secondary and post-hoc analyses. Lancet Neurol. 2015;14(12):1171-1181.

43. Rountree SD, Atri A, Lopez OL, Doody RS. Effectiveness of antidementia drugs in delaying Alzheimer's disease progression. Alzheimers Dement. 2013;9(3):338-345.

44. Atri A, Shaughnessy LW, Locascio JJ, Growdon JH. Long-term course and effectiveness of combination therapy in Alzheimer disease. Alzheimer Dis Assoc Disord. 2008;22(3):209-221.

45. Lopez OL, Becker JT, Wahed AS, et al. Long-term effects of the concomitant use of memantine with cholinesterase inhibition in Alzheimer disease. J Neurol Neurosurg Psychiatry. 2009;80(6):600-607.

46. Birks J, Harvey RJ. Donepezil for dementia due to Alzheimer's disease. Cochrane Database Syst Rev. 2006;(1):CD001190.

47. Winblad B, Jones RW, Wirth Y, Stoffler A, Mobius HJ. Memantine in moderate to severe Alzheimer's disease: a meta-analysis of randomised clinical trials. Dement Geriatr Cogn Disord. 2007;24(1):20-27.

48. Gill SS, Anderson GM, Fischer HD, et al. Syncope and its consequences in patients with dementia receiving cholinesterase inhibitors: a population-based cohort study. Arch Intern Med. 2009;169(9):867-873.

49. Park-Wyllie LY, Mamdani MM, Li P, Gill SS, Laupacis A, Juurlink DN. Cholinesterase inhibitors and hospitalization for bradycardia: a population-based study. PLoS Med. 2009;6(9):e1000157.

50. Sheffrin M, Miao Y, Boscardin WJ, Steinman MA. Weight loss associated with cholinesterase inhibitors in individuals with dementia in a national healthcare system. J Am Geriatr Soc. 2015;63(8):1512-1518.

51. Kim DH, Brown RT, Ding EL, Kiel DP, Berry SD. Dementia medications and risk of falls, syncope, and related adverse events: metaanalysis of randomized controlled trials. J Am Geriatr Soc. 2011;59(6): 1019-1031.

52. Mayer M, Pulte I. How safe is combination memantine/donepezil treatment in people with Alzheimer's disease? Safety evaluations based on 23 clinical studies. Alzheimers Dement. 2013;9(Suppl 4):P282.

53. Perhach J, Graham S. A long-term, open-label extension study evaluating the safety of extended-release memantine $(28 \mathrm{mg})$ in patients with moderate to severe Alzheimer's disease. Alzheimers Dement. 2011; 7(Suppl 4):e70.

54. Saint-Laurent Thibault C, Ozer Stillman I, Chen S, et al. Cost-utility analysis of memantine extended release added to cholinesterase inhibitors compared to cholinesterase inhibitor monotherapy for the treatment of moderate-to-severe dementia of the Alzheimer's type in the US. $J$ Med Econ. 2015;18(11):930-943.

55. Weycker D, Taneja C, Edelsberg J, et al. Cost-effectiveness of memantine in moderate-to-severe Alzheimer's disease patients receiving donepezil. Curr Med Res Opin. 2007;23(5):1187-1197.

56. Touchon J, Lachaine J, Beauchemin C, Granghaud A, Rive B, Bineau S. The impact of memantine in combination with acetylcholinesterase inhibitors on admission of patients with Alzheimer's disease to nursing homes: cost-effectiveness analysis in France. Eur J Health Econ. 2014; 15(8):791-800.

57. Lachaine J, Beauchemin C, Legault M, Bineau S. Economic evaluation of the impact of memantine on time to nursing home admission in the treatment of Alzheimer disease. Can J Psychiatry. 2011; 56(10):596-604.
58. Rountree SD, Chan W, Pavlik VN, Darby EJ, Siddiqui S, Doody RS. Persistent treatment with cholinesterase inhibitors and/or memantine slows clinical progression of Alzheimer disease. Alzheimers Res Ther. 2009;1(2):7.

59. Bangalore S, Kamalakkannan G, Parkar S, Messerli FH. Fixed-dose combinations improve medication compliance: a meta-analysis. $\mathrm{Am} J$ Med. 2007;120(8):713-719.

60. Thom S, Poulter N, Field J, et al. Effects of a fixed-dose combination strategy on adherence and risk factors in patients with or at high risk of CVD: the UMPIRE randomized clinical trial. JAMA. 2013;310(9):918-929.

61. Maxwell CJ, Stock K, Seitz D, Herrmann N. Persistence and adherence with dementia pharmacotherapy: relevance of patient, provider, and system factors. Can J Psychiatry. 2014;59(12):624-631.

62. Herrmann N, Binder C, Dalziel W, Smyth S, Camacho F. Persistence with cholinesterase inhibitor therapy for dementia: an observational administrative health database study. Drugs Aging. 2009;26(5):403-407.

63. Borah B, Sacco P, Zarotsky V. Predictors of adherence among Alzheimer's disease patients receiving oral therapy. Curr Med Res Opin. 2010;26(8):1957-1965.

64. Tian H, Abouzaid S, Chen W, Kahler KH, Kim E. Patient adherence to transdermal rivastigmine after switching from oral donepezil: a retrospective claims database study. Alzheimer Dis Assoc Disord. 2013; 27(2):182-186.

65. Brewer L, Bennett K, McGreevy C, Williams D. A population-based study of dosing and persistence with anti-dementia medications. Eur J Clin Pharmacol. 2013;69(7):1467-1475.

66. Olazaran J, Navarro E, Rojo JM. Persistence of cholinesterase inhibitor treatment in dementia: insights from a naturalistic study. Dement Geriatr Cogn Dis Extra. 2013;3(1):48-59.

67. Pariente A, Pinet M, Moride Y, Merliere Y, Moore N, Fourrier-Reglat A. Factors associated with persistence of cholinesterase inhibitor treatments in the elderly. Pharmacoepidemiol Drug Saf. 2010;19(7):680-686.

68. Alagiakrishnan K, Bhanji RA, Kurian M. Evaluation and management of oropharyngeal dysphagia in different types of dementia: a systematic review. Arch Gerontol Geriatr. 2013;56(1):1-9.

69. Strachan I, Greener M. Medication related swallowing difficulties may be more common than we realize. Pharm Pract. 2005;15(9):411-414.

70. Marquis J, Schneider MP, Payot V, et al. Swallowing difficulties with oral drugs among polypharmacy patients attending community pharmacies. Int J Clin Pharm. 2013;35(6):1130-1136.

71. Haw C, Stubbs J, Dickens G. An observational study of medication administration errors in old-age psychiatric inpatients. Int $J$ Qual Health Care. 2007;19(4):210-216.

72. Stegemann S, Gosch M, Breitkreutz J. Swallowing dysfunction and dysphagia is an unrecognized challenge for oral drug therapy. Int $J$ Pharm. 2012;430(1-2):197-206.

73. Hauber AB, Gnanasakthy A, Snyder EH, Bala MV, Richter A, Mauskopf JA. Potential savings in the cost of caring for Alzheimer's disease. Treatment with rivastigmine. Pharmacoeconomics. 2000;17(4): 351-360.

74. Neumann PJ, Hermann RC, Kuntz KM, et al. Cost-effectiveness of donepezil in the treatment of mild or moderate Alzheimer's disease. Neurology. 1999;52(6):1138-1145.

75. Jelic V, Winblad B. Alzheimer disease. Donepezil and nursing home placement-benefits and costs. Nat Rev Neurol. 2016;12(1):11-13.

76. Karlawish JH, Klocinski JL, Merz J, Clark CM, Asch DA. Caregivers' preferences for the treatment of patients with Alzheimer's disease. Neurology. 2000;55(7):1008-1014.

77. Yaffe K, Fox P, Newcomer R, et al. Patient and caregiver characteristics and nursing home placement in patients with dementia. JAMA. 2002; 287(16):2090-2097.

78. Hatoum HT, Thomas SK, Lin SJ, Lane R, Bullock R. Predicting time to nursing home placement based on activities of daily living scores - a modelling analysis using data on Alzheimer's disease patients receiving rivastigmine or donepezil. J Med Econ. 2009;12(2):98-103. 
79. Alva G, Ellison N, Dass B, Hendrix S. Daily functioning benefits of adding memantine to stable cholinesterase treatment in patients with moderate to severe Alzheimer's disease: a post hoc pooled factor analysis (P2.218). Neurology. 2016;86(Suppl 16).

80. New York Schneiderman v. Actavis PLC LLC. FindLaw. 2015. Available from: http://caselaw.findlaw.com/us-2nd-circuit/1702157.html. Accessed May 17, 2016.
81. Upsher-Smith receives FDA approval for generic version of Namenda (Memantine $\mathrm{HCl}$ ) tablets. PRNewswire. 2015. Available from: http:// www.prnewswire.com/news-releases/upsher-smith-receives-fdaapproval-for-generic-version-of-namenda-memantine-hcl-tablets300125957.html. Accessed May 17, 2016.

\section{Publish your work in this journal}

Drug Design, Development and Therapy is an international, peerreviewed open-access journal that spans the spectrum of drug design and development through to clinical applications. Clinical outcomes, patient safety, and programs for the development and effective, safe, and sustained use of medicines are the features of the journal, which has also been accepted for indexing on PubMed Central. The manuscript management system is completely online and includes a very quick and fair peer-review system, which is all easy to use. Visit http://www.dovepress.com/testimonials.php to read real quotes from published authors.

Submit your manuscript here: http://www.dovepress.com/drug-design-development-and-therapy-journal 